\title{
O PROFISSIONAL DA INFORMÁTICA E SUA PERSONALIDADE ANALISADA POR MEIO DA TÉCNICA DE RORSCHACH ${ }^{1}$
}

\author{
Seille Cristine Garcia Santos \\ Cícero Emidio Vaz
}

\begin{abstract}
RESUMO. Este artigo apresenta os resultados de um estudo comparativo da capacidade de análise, iniciativa e relacionamento humano entre informatas gerentes e operacionais. Participaram 66 informatas, de 9 empresas e 5 departamentos de informática com até 150 funcionários, de Porto Alegre e Grande Porto Alegre. Foram utilizados a técnica de Rorschach (Sistema Klopfer) e um questionário estruturado. O mesmo questionário foi respondido pelo superior imediato de cada participante do estudo. Os resultados mostram que não existem diferenças significativas (t-Test e correlação de Pearson) entre informatas gerentes e informatas operacionais com relação à capacidade de análise, iniciativa e relacionamento humano. Os operacionais se diferenciam dos gerentes no que diz respeito à liberação das reações emocionais com menos controle. É discutida a presença em ambos os grupos de indicativos no Rorschach de dificuldades para interagir com outras pessoas.
\end{abstract}

Palavras-chave: Rorschach, informatas, relacionamento humano.

\section{THE INFORMATION TECHNOLOGY PROFESSIONALS AND THEIR PERSONALITY ANALYZED BY RORSCHACH TECHNIQUE}

\begin{abstract}
This article presents the outcome of a comparative study carried out about the analysis capabilities, initiative, and human relationship among IT (Information Technology) managers and IT systems analysts and programmers. Sixty-six IT individuals from nine different companies and five IT divisions with up to 150 employees working in Porto Alegre and its metropolitan region were surveyed. The Rorschach's technique (Klopfer System) and a structured questionnaire were applied. The same questionnaire was answered by the immediate superior of each subordinate surveyed by this study. The results show that there is no significant difference (t-Test and Pearson correlation) between IT managers and IT systems analysts and programmers regarding their analysis capabilities, initiative and human relationship. The operational individuals distinguish themselves from the managerial ones regarding the release of less controlled emotional reactions. Difficulties to interact with others based on Rorschach's indicatives are discussed in both groups.
\end{abstract}

Key words: Rorschach, IT professionals, human relationship.

Os últimos anos foram marcados pelo grande desenvolvimento tecnológico em vários segmentos. A associação dos computadores com as telecomunicações e os recursos de informação originou a revolução tecnológica em que vivemos, promovendo alterações no modo de vida das pessoas por meio da criação de soluções informatizadas em praticamente todos os campos da vida humana. Esta transformação proporcionou o surgimento de profissões novas no campo da informática, contribuindo assim para o suprimento da demanda de manufatura de hardware e software cada vez mais complexos.

O desenvolvimento de software é uma das atividades da tecnologia de informação. Exige do profissional da informática, a quem chamaremos informata, competências diversificadas e investimentos financeiros vultosos por parte das empresas, instituições e governos. O escopo do software a ser construído define o número e a qualificação dos profissionais que serão necessários na equipe. De maneira geral, além do gerente, a equipe

\footnotetext{
Apoio: Capes.

* Psicóloga. Mestre em Psicologia pela Pontifícia Universidade Católica do Rio Grande do Sul-PUCRS, Consultora de Recursos Humanos.

\# Doutor em Psicologia. Docente Titular do Programa de Pós-Graduação da Pontifícia Universidade Católica do Rio Grande do Sul-PUCRS.
} 
pode ser constituída de engenheiros de software, analistas de sistemas, analistas de negócios e programadores.

Do desempenho do gerente depende o êxito de um projeto de desenvolvimento de software. Para executar as tarefas de planejamento, organização e distribuição das tarefas, coordenação e acompanhamento da equipe, o informata gerente, além do conhecimento técnico e de negócio, necessita ter abrangente visão do ser humano, ser capaz de se comunicar, ouvir, dar e receber feedback, solucionar conflitos e respeitar diferenças.

As atividades operacionais no desenvolvimento de software, em geral sob a responsabilidade de analistas de sistemas e programadores, consistem em executar o Ciclo de Desenvolvimento de Software, que compreende as etapas de conceituação do software, análise dos requisitos, design e arquitetura, detalhamento do design, codificação e teste do sistema.

Investigar em que se diferenciam e em que se assemelham o informata em função gerencial e o informata no desempenho de funções operacionais, é o objetivo deste estudo.

\section{ADMINISTRAÇÃO E INFORMÁTICA: ATIVIDẢDE GERENCIAL}

A Administração tem seus primórdios na antiguidade. Foram encontrados registros que sugeriam a utilização de práticas de planejamento, administração pública, organização, condução de trabalhadores e hierarquia no Egito antigo, na Mesopotâmia, na Grécia, na China e na Roma antiga, cada um a seu tempo (Faria, 1994; Hampton, 1990).

Para chegar ao ponto em que estamos, a Administração passou por inúmeras fases, que suscitaram diversos estudos. O primeiro curso de Administração surgiu nos Estados Unidos em 1881 e no Brasil, por volta de 1950. Desde então, estudiosos da área buscam identificar as melhores técnicas e processos para administrar, que em termos gerais significa atingir objetivos por meio da ação dos membros da organização (Megginson, Mosley \& Pietri, 1986). Conforme Hampton (1990), Faria (1994) e Barros Neto (2002), a Administração Científica, a Teoria Clássica e a Teoria das Relações Humanas fundamentam a Administração e servem como ponto de partida para a discussão da Administração contemporânea.

A divisão do trabalho entre gerência e trabalhadores operacionais foi criada por Taylor (1911/1995) e desenvolvida por Fayol (1916/1994), com a definição de cinco funções gerenciais: planejamento, organização, direção, coordenação e controle:

- Planejamento: entendido como processo de construção do plano de trabalho considerando objetivos, atividades e recursos, decidindo o que fazer e como fazer antecipadamente; é, em essência, presidir as ações.

- Organização: processo de definição das responsabilidades sobre o que deve ser realizado; ordem de execução e aplicação dos recursos seguindo o planejamento.

- Direção: processo de movimentação das pessoas para realizar as atividades que conduzirão aos objetivos traçados no planejamento, por meio da motivação, comunicação e liderança efetiva.

- Coordenação: processo de integrar as partes do trabalho que foi dividido entre setores e pessoas, sintonizando-as com os objetivos do planejamento.

- Controle: processo de assegurar a realização dos objetivos do planejamento com a utilização dos recursos nos prazos planejados.

$\mathrm{Na}$ década de 1960 McGregor (1960/1992) apresentou uma nova concepção de gerência, com visão positiva de seus subordinados, como pessoas capazes, responsáveis, colaborativas, altruístas e dispostas a fazer um bom trabalho. Drucker (1967) definiu gerente como o profissional que, em virtude de sua posição e de seu conhecimento, é "responsável por uma contribuição que afeta, materialmente, a capacidade da organização de trabalhar e de obter resultados" (p. 5).

Com o contínuo estudo da Administração, Mintzberg (1975) sugeriu a classificação do trabalho gerencial em dez papéis, agrupados em três dimensões: papéis interpessoais (imagem do chefe, líder, contato); papéis informacionais (monitor, disseminador e porta-voz); e papéis decisoriais (empreendedor, manipulador de distúrbios, alocador de recursos e negociador).

No Brasil, na década de 1990, Motta (2002) expôs o entendimento da função gerencial como "ambígua e repleta de dualidades, cujo exercício se faz de forma fragmentada e intermitente" (p. 20), pois muitos gerentes relatam grande número de trabalhos inusitados numa carga de tarefas imprevistas, reuniões, telefonemas e interrupções constantes de forma descontínua e variável, exigindo de si mesmos estrutura psicológica para suportar alto grau de pressão. A pessoa nesta função necessita ter o que o 
autor denominou capacidade gerencial, que é a conjugação de: capacidade de analisar e julgar, decidir e ter iniciativa, enfrentar riscos e incertezas; capacidade de negociar e liderar pessoas. A capacidade gerencial não se limita ao domínio de técnicas administrativas; compreende também o desenvolvimento de habilidades e atitudes; envolve conhecimento de si próprio, do papel que ocupa na organização, do contexto em que está inserido e principalmente do comprometimento que deve ter para com a empresa em que trabalha.

Atualmente, Mintzberg e Gosling (2003) sugerem que há pessoas com inclinação para as funções gerenciais, e isto pode ser observado a partir das características individuais e de personalidade. Os autores enfatizam a existência de estados da "mente administrativa", que são compostos por inclinações reflexivas, colaborativas, analíticas, voltadas para o mundo e para a ação.

As tarefas gerenciais no desenvolvimento de software não são diferentes das atividades de um gerente de outra área. Conforme Cheney, Hale e Kasper (1989), Kraut e Streeter (1995), McConnell (1996) e Stábile (2001), os fundamentos do gerenciamento no desenvolvimento de software consistem em: dimensionar o trabalho necessário para desenvolver o produto (incluindo funcionalidades, complexidade e características); alocar recursos apropriadamente, de acordo com o tamanho do produto; criar um plano para aplicar, monitorar e dirigir os recursos, acompanhando o progresso no desenvolvimento de cada fase. Além disto é necessário ao gerente conhecer as regras de negócio, ter visão do todo, estar atento a detalhes que possam interferir no andamento do trabalho, ter bom relacionamento interpessoal e comunicar-se adequadamente com os usuários, a alta direção, os pares e membros de sua equipe operacional.

As atividades operacionais são delegadas aos analistas de sistemas e programadores que executam o Ciclo de Desenvolvimento de Software (ver McConnell, 1996). Ao analista de sistemas cabe a tarefa de operacionalizar o planejamento, realizando atividades de levantamento e análise de requisitos, especificação e design lógico, acompanhamento da programação e testagem do produto. Ao programador compete implementar as especificações definidas pelo analista de sistemas, codificando-as a partir de linguagens específicas de programação; deve ele testar o seu próprio trabalho antes de encaminhá-lo para a avaliação do analista de sistemas. Analistas de sistemas e programadores devem possuir aprofundado domínio tecnológico, precisam conhecer o negócio da empresa e comunicar-se bem entre si e com usuários, desenvolver senso de equipe e espírito colaborativo.

Quando comparados informatas gerentes com informatas operacionais (analistas de sistemas e programadores), em estudos realizados por pesquisadores de outros países, alguns dos resultados se destacam:

- Sobre as características de personalidade, Moore (1991) nos Estados Unidos aplicou o Sixteen Personality Factor Questionnaire (16PF) em 113 informatas. Encontrou resultados significativos que sugeriram a tendência dos informatas gerentes, comparados aos operacionais, a serem mais impulsivos e competitivos, possuírem alta capacidade para pensamento abstrato, inclinação para analisar e solver problemas e interesse por liderar e persuadir pessoas. Quando comparados com os gerentes de outras áreas, demonstraram pouca capacidade para aventurar-se socialmente e aceitar condições impostas por outros; demonstraram ser mais agressivos, autosuficientes, impulsivos e tensos do que gerentes de outras áreas.

- Quanto à motivação para o trabalho, no estudo realizado por Couger e O'Callaghan (1993) com 334 participantes espanhóis não foram encontrados resultados significativos quando comparados gerentes e operacionais com relação aos aspectos: identificação com as tarefas, autonomia, capacidade de dar e receber feedback e satisfação com a supervisão recebida. Os autores enfatizam que os dois grupos apresentam baixa necessidade de interação social, confirmando pesquisas anteriores finlandesas e americanas. Afirmam Couger e O'Callaghan que as pessoas atraídas pelo trabalho com computador sentem-se bem sozinhas.

- No que diz respeito a características dos desenvolvedores de software, Wynekoop e Walz (1998), após a aplicação do The Califórnia Psychological Inventory Adjetive Check List (ACL) em 114 informatas gerentes e operacionais, afirmaram que, em comparação com a população em geral, os informatas desta amostra são ambiciosos, lógicos e conservadores, demonstram também ser analíticos, produtivos e persistentes. Os programadores tendem a ser menos sociáveis e mais resistentes a mudanças que analistas de sistemas e gerentes. Os analistas de sistemas e gerentes tendem a estabelecer relacionamentos 
sociais cautelosos e prudentes, podem não demonstrar sociabilidade no convívio com outras pessoas.

$\mathrm{Na}$ literatura revisada observa-se estreita relação entre o sucesso no desenvolvimento de software e o gerenciamento da equipe; o estilo de coordenação, as características de personalidade e a habilidade do gerente em conduzir pessoas são aspectos decisivos para o bom desempenho da equipe. Conforme Bradley e Hebert (1997) e Gorla e Lam (2004), o melhor gerente para uma equipe de desenvolvimento de software é aquele que tem capacidade de comunicação e é extrovertido; é capaz de observar detalhes sem perder a visão do todo; tem bem desenvolvido o pensamento lógico-analítico e toma decisões de forma racional; é atento às pessoas e prefere viver de forma planejada, controlada e ordenada.

\section{CARREIRA DO INFORMATA}

É bastante comum encontrarmos, nas empresas de desenvolvimento de software, gerentes que iniciaram a sua carreira como programadores ou digitadores. Observando a ocupação dos cargos nas organizações é comum encontrarmos cargos gerenciais sendo ocupados por excelentes técnicos, levados em grande parte pela expectativa de seus diretores de terem bom desempenho como técnicos, de que sejam também bons gerentes; ou ainda levados pelo interesse pessoal em melhor remuneração. É um paradigma a ser discutido, tendo-se em vista que a escolha por esta carreira profissional deveria ser pautada por preferência pessoal, por um conjunto facilitador de conhecimentos, habilidades e atitudes gerenciais e pela caracterização de personalidade favorável ao desenvolvimento dos processos de gestão, como sugerem Mintzberg e Gosling (2003).

Relata Assis (2002) que na década de 1970 surgiu no Brasil a carreira paralela ou de estrutura em Y. Por estrutura Y entende-se uma organização dos cargos de forma a permitir que, a partir de um determinado ponto da estrutura hierárquica, seja possível crescer funcionalmente para o braço gerencial (numa perna do Y) ou para o braço técnico (na outra perna do Y) com equivalência salarial.

Acreditamos, como Wynekoop e Walz (1998), Faraj e Sproull (2000), que ainda estamos na fase inicial da discussão da carreira do informata, pois, além de a profissão ser nova, as características de personalidade encontradas em pesquisas existentes são complexas e os grupos funcionais - quer de gerentes, quer analistas de sistemas, quer de programadores - são bastante diferentes. Em cada posição hierárquica é necessário agregar novas habilidades. Em princípio, este parece ser o traçado da carreira do informata: programador $\rightarrow$ analista de sistemas $\rightarrow$ gerente.

A formação do informata situa-se na área de ciências exatas, nos cursos de graduação em ciências da computação, sistemas de informação, engenharia de software, entre outros, que parecem proporcionar preparo para desempenhar tarefas do desenvolvimento de software. A escolha por esta carreira profissional pressupõe gosto pela área lógico-matemática, por cálculos, pelo trabalho com dados e por investigação de conceitos, situações e processos (Holland, 1997). O trabalho gerencial supõe e tem como um dos prérequisitos o contato humano, o relacionamento estreito com outras pessoas, processos profundos de comunicação para que ocorra a coordenação do trabalho e o bom desempenho nas atividades. A expertise em coordenar tem forte relação com a performance da equipe (Faraj \& Sproull, 2000).

Seguindo o pensamento de Motta (2002), a pessoa que ocupa função gerencial necessita ter capacidade gerencial, que não se limita ao domínio das técnicas administrativas, sendo imprescindível desenvolver a capacidade de análise para compreensão dos dados disponíveis, iniciativa para implementar as decisões e capacidade para lidar com pessoas (relacionamento interpessoal).

\section{Termos operacionais}

Capacidade de análise: além de ser um princípio conceitual da administração, é um aspecto da personalidade importante, incluindo senso crítico para adquirir e interpretar as informações acerca de um assunto, envolvendo a capacidade de entender o relacionamento das partes com o todo, e o todo dividido em partes, conforme Megginson, Mosley e Pietri (1986). A análise precede a tomada de decisão na capacidade de apreender dados e estabelecer critérios de escolha.

Iiniciativa: entende-se por iniciativa a disposição para prover idéias e assumir riscos, envolvendo o grupo de pessoas subordinadas diretamente ao gerente ou a organização como um todo. É entendida como a possibilidade de conceber e executar, com a liberdade de propor, conforme (Fayol, 1994).

Relacionamento humano: a habilidade da pessoa de compreender as demais, interagir efetivamente com elas e de estabelecer vínculo afetivo adequado às condições de trabalho.

A função gerencial é complexa e tem seu berço nas ciências humanas; o trabalho do informata é 
vinculado às ciências exatas, fundamenta-se na lógica e na racionalidade da máquina. Como combinar com a carreira gerencial? Os aspectos referentes à capacidade de análise, iniciativa e relacionamento humano são diferentes no informata gerente quando comparado ao informata operacional? Ou será que as pessoas ocupantes destas duas funções, gerencial ou operacional, são semelhantes quanto a estes aspectos? Responder a estas questões é o objetivo deste estudo.

\section{PROBLEMA E HIPÓTESES}

Este estudo propõe-se a investigar diferenças entre o informata gerente e o informata operacional, com relação aos aspectos de personalidade, capacidade de análise, iniciativa e relacionamento humano.

$\mathrm{Na}$ tentativa de buscar resposta ao problema foram formuladas as seguintes hipóteses:

H1. Informatas gerentes apresentam indicativos de capacidade de análise mais elevados que os informatas operacionais.

H2. Informatas gerentes apresentam índices mais elevados de capacidade de iniciativa que os informatas operacionais.

H3. Informatas gerentes apresentam indicativos de condições de relacionamento humano mais elevados do que os informatas operacionais.

\section{MÉTODO}

\section{Amostra e instrumentos}

A amostra, por conveniência, foi constituída de 66 informatas, funcionários de 9 empresas de informática e 5 departamentos de informática com até 150 funcionários situados em Porto Alegre e na Grande Porto Alegre. Todos os participantes são do sexo masculino. A média de idade para os informatas gerentes é de 35,5 anos e para os informatas operacionais é de 29,3 anos. Todos concluíram a graduação em cursos na área de informática. Trinta e três informatas ocupam funções gerenciais (G1) e os demais informatas participantes, funções operacionais (G2), análise de sistemas (21) e programação (12).

Técnica de Rorschach: método elaborado por Hermann Rorschach (1921) na Suíça. É uma técnica projetiva construída para estudo da estrutura e do funcionamento da personalidade e seus psicodinamismos. O sistema adotado é o de Bruno Klopfer, com adaptação de Vaz (1997). As variáveis compatíveis com o que se busca avaliar nas hipóteses são: o número de respostas (R), detalhe comum (D) e detalhe incomum (Dd) para verificar a capacidade de análise; os determinantes movimento animal (FM) e cor e forma (CF) na observação da capacidade de iniciativa; e os determinantes movimento humano (M), forma e cor (FC), na avaliação do relacionamento humano.

Questionário 1: para gerentes e operacionais, foi construído um questionário com 28 afirmativas, referentes à capacidade de análise, iniciativa, relacionamento humano e escolha profissional, com cinco opções de resposta numa escala Likert. O questionário foi aplicado, na fase piloto, em 10 informatas gerentes e 10 informatas operacionais, convidados pela pesquisadora. Foi observado o Alpha de Cronbach para verificar a consistência interna de cada questão. Foram aceitas para o questionário a ser utilizado na pesquisa as questões que tiveram Alpha superior a 0,5 . O questionário final, resultante da fase piloto, contou com 14 afirmativas (cinco referentes à capacidade de análise, três para iniciativa, quatro para relacionamento humano e duas para escolha profissional) e dados de identificação do participante (sexo, idade, formação, função). $\mathrm{O}$ objetivo deste questionário (escala Likert 1 a 5) foi avaliar a percepção do informata a respeito de si mesmo em relação aos aspectos em questão (capacidade de análise, iniciativa e relacionamento humano) por meio de afirmativas do tipo: "Sou capaz de detalhar itens de um assunto, problema ou situação"; "Sinto-me capaz de compreender as pessoas que se relacionam diretamente comigo no trabalho".

Questionário 2 - para superior imediato: as 14 afirmativas do questionário para os informatas gerentes e operacionais foram transformadas em 14 indagações com cinco opções de resposta, escala de Likert, a serem aplicadas ao superior imediato de cada participante, objetivando investigar a percepção sobre o subordinado com relação às variáveis investigadas: capacidade de análise, iniciativa, relacionamento.

\section{Procedimento}

O Projeto foi submetido à avaliação do Comitê de Ética em Pesquisa da PUCRS. Posteriormente a esta aprovação, foram contatadas, por meio do departamento de Recursos Humanos, empresas de desenvolvimento de software ou departamentos de informática com até 150 funcionários, de Porto Alegre e da Grande Porto Alegre. Após receberem explicações sobre os objetivos da pesquisa e procedimentos, catorze empresas manifestaram interesse em participar e autorizaram a divulgação 
interna para seus funcionários. Foram agendados horários individuais para aplicação do Rorschach e do Questionário1 com os informatas voluntários, após receberem as explicações acerca do estudo e terem assinado o Termo de Consentimento Livre e Esclarecido. O Questionário 2 foi encaminhado por $e$ mail para o superior imediato de cada participante com solicitação de devolução em até cinco dias.

\section{RESULTADOS E DISCUSSÃO}

A classificação (Localizações, Determinantes e Conteúdos) dos protocolos do Rorschach foi realizada às cegas e sucessivamente por três juízes, integrantes do Grupo de Pesquisa Personalidade, Cultura e Técnicas Projetivas (Programa de Pós-Graduação em Psicologia da PUCRS). Foram utilizados para estudo estatístico a análise de variância - ANOVA, o teste t e o coeficiente de correlação de Pearson; e para todas as análises estatísticas, o nível de significância para aceitação das hipóteses alternativas • 0,05. Após análise dos dados chegamos aos seguintes resultados para as hipóteses:

a) Não se confirmou a hipótese de que os informatas gerentes (G1) apresentam indicativos de capacidade de análise em índice mais elevado que os informatas operacionais (G2). Em nenhuma destas variáveis $\mathrm{R}(\mathrm{G} 1=$ média 19,2 e G2= média 17,9), D\% (G1=23,2 e G2=22,8) e Dd\% (G1=23,4 e G2=29,0) do Rorschach houve diferença de média significativa entre os dois grupos (Tabela 1).

Tabela 1. Tabela comparativa entre grupo de gerentes (G1) e o grupo de operacionais (G2) com relação ao número de respostas $(\mathrm{R})$ e às localizações (D e Dd)

\begin{tabular}{lccccc}
\hline \multirow{2}{*}{ Grupo de Informatas } & \multicolumn{5}{c}{ Respostas e Localizações } \\
\cline { 2 - 6 } & R & D & D\% & Dd & Dd\% \\
\hline Gerentes (n=33) & & & & & \\
Média & 19,2 & 4,7 & 23,2 & 5,9 & 23,4 \\
DP & 10,2 & 3,6 & 10,8 & 7,1 & 19,5 \\
Var & 103,8 & 13,0 & 116,3 & 50,2 & 379,1 \\
Mínimo & 9,0 & 0,0 & 0,0 & 0,0 & 0,0 \\
Máximo & 41,0 & 15,0 & 46,9 & 26,0 & 64,3 \\
\hline Operacionais (n=33) & & & & & \\
Média & 17,9 & 4,4 & 22,8 & 5,8 & 29,0 \\
DP & 8,8 & 3,6 & 11,5 & 5,6 & 18,2 \\
Var & 77,2 & 12,9 & 131,7 & 31,6 & 331,2 \\
Mínimo & 10,0 & 0,0 & 0,0 & 0,0 & 0,0 \\
Máximo & 44,0 & 17,0 & 58,3 & 25,0 & 62,5 \\
\hline
\end{tabular}

Fórmula para média de $\mathrm{R}=\Sigma \mathrm{R} / 33$ por grupo. Fórmula para percentual de $\mathrm{D} \%$ e $\mathrm{Dd} \%$ = (D/média de R)/100 e (Dd/média de R) 100 . b) A hipótese de que o (G1) apresenta indicadores de capacidade de iniciativa em índice mais elevado que o (G2) não se confirmou pelo indicador FM ( $\mathrm{G} 1=13,4$ e $\mathrm{G} 2=11,98)$, uma vez que o nível de significância foi $p=0,51$. Na comparação do percentual médio de respostas quanto ao determinante $\mathrm{CF}$ obtivemos a média para o G1 de 0,8 e para o G2 de 2,1 com $p=0,04$. É possível afirmar que os dois grupos têm condições de tomar iniciativa, sendo que os operacionais (G2) apresentam índice de Cor e Forma (CF) maior do que os informatas gerentes, o que corresponde a dizer que tendem a reações emocionais com menos controle. Podemos dizer que o G2 se assemelha ao G1 quanto ao dinamismo (FM), mas se diferencia no que diz respeito à liberação das reações emocionais $(\mathrm{CF})$.

c) Não se confirmou a hipótese de o G1 apresentar indicativos de condições de relacionamento humano mais elevadas do que o G2. Verifica-se não haver diferença significativa quanto ao percentual médio para os determinantes $m$ $(\mathrm{G} 1=12,8$ e $\mathrm{G} 2=12,5)$ e $\mathrm{FC}(\mathrm{G} 1=6,5$ e $\mathrm{G} 2=6,0)$ na comparação entre os dois grupos (Tabela 2).

Tabela 2. Tabela comparativa entre o grupo de gerentes e operacionais com relação aos determinantes (FM, CF, $\mathrm{M}$ e FC). Há diferença significativa entre os dois grupos para o determinante $\mathrm{CF}, p=0,04$

\begin{tabular}{|c|c|c|c|c|c|c|c|c|}
\hline \multirow{2}{*}{$\begin{array}{l}\text { Grupo de } \\
\text { Informatas }\end{array}$} & \multicolumn{8}{|c|}{ Determinantes } \\
\hline & FM & $\begin{array}{c}\text { FM } \\
\%\end{array}$ & $\mathbf{C F}$ & CF\% & $\mathbf{M}$ & M\% & FC & $\begin{array}{c}\text { FC } \\
\%\end{array}$ \\
\hline \multicolumn{9}{|c|}{ Gerentes $(n=33)$} \\
\hline Média & 2,5 & 13,4 & 0,2 & 0,8 & 2,3 & 12,8 & 1,3 & 6,5 \\
\hline DP & 2,4 & 9,3 & 0,4 & 1,8 & 1,7 & 9,8 & 1,4 & 6,8 \\
\hline Var & 5,6 & 86,8 & 0,2 & 3,6 & 3,0 & 97,7 & 2,0 & 46,6 \\
\hline línimo & 0 & 0,0 & 0 & 0,0 & 0 & 0,0 & 0 & 0,0 \\
\hline Máximo & 13 & 40,0 & 1 & 8,3 & 7 & 40,0 & 5 & 30,0 \\
\hline \multicolumn{9}{|c|}{ Operacionais $(n=33)$} \\
\hline Média & 2,1 & 11,98 & 0,5 & 2,1 & 2,0 & 12,5 & 1,2 & 6.0 \\
\hline DP & 1,5 & 7,82 & 0,6 & 2,9 & 1,5 & 10,0 & 1,2 & 6,4 \\
\hline Var & 2,1 & 61,2 & 0,4 & 9,0 & 2,3 & 101,7 & 1,4 & 40,8 \\
\hline ínimo & 0 & 0,0 & 0 & 0,0 & 0 & 0,0 & 0 & 0,0 \\
\hline Máximo & 5 & 30,0 & 2 & 9,1 & 7 & 36,4 & 5 & 20,0 \\
\hline \multicolumn{9}{|c|}{$\begin{array}{l}\text { Fórmula para percentual deFM\%, CF\%, M\% e FC\% = }(\mathrm{FM} / \text { média de } \\
\mathrm{R}) / 100 ;(\mathrm{CF} / \text { média de R) } \mathrm{R} 100 ;(\mathrm{M} / \text { média de } \mathrm{R}) / 100 \text { e } \mathrm{FC} / \text { média de } \\
\mathrm{R} / 100) \text {. }\end{array}$} \\
\hline \multicolumn{9}{|c|}{$\begin{array}{l}\text { Levando em conta o índice de } 3 \text { a } 4 \text { respostas de } \\
\text { M (Vaz, 1997), como esperado quanto à capacidade } \\
\text { de integração e espontaneidade necessária para lidar } \\
\text { com pessoas, observamos que apenas } 6 \text { gerentes e } 4 \\
\text { operacionais deram } 3 \text { ou } 4 \text { respostas de M; } 27(82 \%) \\
\text { gerentes e } 29(88 \%) \text { operacionais deram apenas uma }\end{array}$} \\
\hline
\end{tabular}


ou nenhuma resposta de M. Este resultado pode ser interpretado como sinal de dificuldades para interagir com outras pessoas, ser empático e integrar-se a grupos, tanto para o G1 quanto para o G2.

Quando partimos para a análise qualitativa do determinante movimento humano (M) encontramos em 7 gerentes e 11 operacionais o determinante movimento humano de má qualidade (Vaz, 1997) ou de tipo secundário M- (Vaz, 2002), que, segundo o autor (1997, p. 90), é mais "comum em casos de pessoas inibidas, ansiosas e de relacionamento interpessoal receoso e tenso". Levando em conta a caracterização exposta na literatura a respeito dos informatas e os resultados observados no G1 e G2, concluímos que estes grupos parecem apreciar trabalhar sozinhos e seus relacionamentos tendem a ser cautelosos e às vezes impessoais. Estes dados corroboram os achados de Couger e O'Callaghan (1993); Wynekoop e Walz (1998); Oliveira (1999); Santos e Vaz (2004). Esta caracterização confronta o pré-requisito de relacionamento humano positivo enfatizado como fundamental para a função de gerente por teóricos como Barnard (1968), Mcgregor (1992) e Moscovici (2003).

\section{Outros achados}

- A proporção entre as localizações globais $(\mathrm{G})$ e o determinante movimento humano (M) no Rorschach pode ser interpretada como nível de aspiração e ambição do examinando (Klopfer, 1952), sendo $2 \mathrm{G}: 1 \mathrm{M}$ o índice esperado em pessoas consideradas normais. No G1 e G2, em 100\% dos casos obtivemos a proporção $\mathrm{G}: \mathrm{M}$ bastante dilatada para G, o que pode ser entendido, segundo Klopfer, como nível de aspiração acima das potencialidades dos participantes da pesquisa.

- Foram comparados por meio do teste $t$ os resultados do Questionário1 respondido pelos gerentes (G1) e as respostas dadas ao Questionário 2 pelos superiores dos gerentes. Não houve diferença significativa na comparação das médias nos aspectos: capacidade de análise (G1 e superior $=4,68)$, iniciativa $(\mathrm{G} 1=4,22$ e superior 4,16$)$ e relacionamento humano $(\mathrm{G} 1=4,25$ e seu superior $=4,38$ ). A percepção dos superiores imediatos confirma a percepção do gerente sobre si mesmo em níveis positivos próximos à nota cinco (5), máxima na escala (Tabela 3).

- Comparando-se os resultados do Questionário 1 respondido pelos operacionais (G2) com as respostas dadas pelos seus superiores imediatos ao Questionário 2, verifica-se que a percepção do informata operacional sobre si mesmo apresenta índices médios maiores do que os índices dos seus superiores. Estas diferenças foram estatisticamente significativas, sugerindo que o G2 não é percebido pelo seu "chefe" como ele se percebe. Para a capacidade de análise $p=0,04$ (G2 =4,69 e seu superior 4,34); no aspecto iniciativa $\mathrm{p}=0,04$ $(\mathrm{G} 2=4,11$ e o seu superior 3,42) e para o relacionamento humano $p=0,05(\mathrm{G} 2=3,89$ e seu superior 3,26) (Tabela 3).

Tabela 3. Tabela comparativa dos índices obtidos em resposta ao Questionário 1 (informatas gerentes e informatas operacionais) e ao Questionário 2 (superior imediato)

\begin{tabular}{|c|c|c|c|c|c|c|}
\hline \multirow{3}{*}{ Grupo } & \multirow{3}{*}{ Índice } & \multicolumn{4}{|c|}{ Avaliação } & \multirow{3}{*}{$\mathbf{p}$} \\
\hline & & \multicolumn{2}{|c|}{ Superior Imediato } & \multicolumn{2}{|c|}{ Informatas } & \\
\hline & & Média & DP & Média & DP & \\
\hline \multirow{3}{*}{ 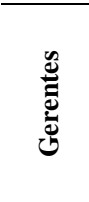 } & $\begin{array}{l}\text { Capacidade de } \\
\text { Análise }\end{array}$ & 4,68 & 0,50 & 4,68 & 0,33 & 1,00 \\
\hline & $\begin{array}{l}\text { Capacidade de } \\
\text { Iniciativa }\end{array}$ & 4,16 & 0,59 & 4,22 & 0,67 & 0,71 \\
\hline & $\begin{array}{l}\text { Relacionamento } \\
\text { Humano }\end{array}$ & 4,38 & 0,79 & 4,25 & 0,39 & 0,47 \\
\hline \multirow{3}{*}{ 莺 } & $\begin{array}{l}\text { Capacidade de } \\
\text { Análise }\end{array}$ & 4,34 & 0,51 & 4,69 & 0,39 & $0,04^{*}$ \\
\hline & $\begin{array}{l}\text { Capacidade de } \\
\text { Iniciativa }\end{array}$ & 3,42 & 1,21 & 4,11 & 0,63 & $0,04 *$ \\
\hline & $\begin{array}{l}\text { Relacionamento } \\
\text { Humano }\end{array}$ & 3,26 & 1,08 & 3,89 & 0,86 & $0,05^{*}$ \\
\hline
\end{tabular}

*Aceito como significativo.

- Utilizando o coeficiente de correlação de Pearson entre as afirmativas do questionário e as variáveis do Rorschach ( $R$, localizações $\mathrm{D}$ e $\mathrm{Dd}$, e determinantes FM, CF, FC e M) não foi encontrada correlação significativa ao nível de 5\%.

Pode-se dizer, a partir dos resultados obtidos nesta amostra, que os informatas que optam pela carreira gerencial não se diferenciam dos informatas operacionais com relação aos aspectos capacidade de análise e relacionamento humano. Os dois grupos têm capacidade de tomar iniciativa, diferenciando-se o G2 na forma de reação emocional menos controlada. Com relação ao aspecto relacionamento humano, $82 \%$ dos gerentes e $89 \%$ dos operacionais aparentam ter dificuldades na interação com outras pessoas. $\mathrm{O}$ grupo gerencial e o grupo operacional são ambiciosos. A percepção de si mesmo no grupo operacional é mais elevada no sentido de seus integrantes serem melhores com relação aos três aspectos do que na percepção do seu superior imediato.

Durante os diálogos mantidos com os participantes da pesquisa surgiram alguns relatos importantes. Um deles foi que é comum aos analistas 
de sistemas serem convidados para assumir função gerencial por conta do seu bom desempenho como técnico operacional. Explicam que alguns são motivados a assumir o novo posto em função da melhor remuneração e outros pela posição hierárquica que assumem na organização; por vezes, desconhecem o que a nova função exigirá.

Pesquisadores do Project Management Institute - PMI explicam que a falta de cumprimento dos prazos e dos orçamentos tem sido comum nos projetos de desenvolvimento de software; isto acontece, em muitos casos, pelo despreparo gerencial, pois quem está ocupando função de gerente pode ser um excelente conhecedor da informática, mas não está instrumentalizado, na teoria e na prática, para gerenciar. A preferência pessoal e a formação de base destes profissionais são orientadas para o trabalho com dados, pensamento abstrato, lógico-matemático, enquanto o trabalho gerencial é orientado para pessoas. Os resultados da pesquisa aqui apresentados confirmam esta realidade. Kanitz (2005) afirma que estamos entrando na "era da administração", e para assumir qualquer função que necessite cumprir as etapas de bem administrar, será necessário aprender e aplicar conceitos administrativos, complementando o pensamento de Motta (2002), que diz ser imprescindível ao gerente ter capacidade gerencial, ou seja, a conjugação da capacidade de analisar, decidir e tomar iniciativa, enfrentar riscos e incertezas, capacidade de negociar e liderar pessoas.

\section{CONSIDERAÇÕES FINAIS}

O primeiro aspecto a ser considerado é que a caracterização da personalidade do informata compreende uma complexidade ainda não estudada em profundidade pelos psicólogos brasileiros. Foram poucos os estudos encontrados durante esta pesquisa. Alguns são trabalhos acadêmicos que muitas vezes não vêm a público.

Ao serem consideradas as diferenças e semelhanças apresentadas, podemos dizer que o informata que opta pela carreira gerencial não se diferencia do informata operacional no que tange aos aspectos capacidade de análise e relacionamento humano. A maioria destes informatas demonstra, por meio dos dados obtidos no Rorschach, dificuldades no relacionamento com grupos humanos. Estes aspectos, a partir da concepção da capacidade gerencial de
Motta (2002), são imprescindíveis para uma pessoa que ambicione ocupar função gerencial.

Apesar de os dois grupos manifestarem capacidade de tomar iniciativa, o grupo gerencial tende a ter mais controle sobre suas emoções que o grupo operacional. Isso talvez possa ser explicado em função da posição hierárquica que ocupam, pela pressão que sofrem e necessidade de maior controle adaptado às tarefas que executam.

Os resultados obtidos nos permitem dizer que o informata pode ser levado a assumir funções hierárquicas superiores por conta de sua aspiração e ambição elevada, sem levar em consideração as capacidades que a nova função exigirá.

Parece ser fundamental sensibilizar o profissional da informática e o dirigente de empresa no que tange a dois aspectos que nos parecem importantes: para desempenhar funções operacionais são necessários conhecimentos técnicos e experiência no trabalho em si; para assumir a função gerencial é necessário ao informata, além do conhecimento técnico, desenvolver habilidades e atitudes gerenciais voltando-se para o trato com pessoas.

\section{REFERÊNCIAS}

Assis, M. T. (2002). Programas de remuneração integrando sistemáticas de recompensa e reconhecimento. Rio de Janeiro: Papel Virtual.

Barnard, C. I. (1968). The functions of the executive. EUA: Harvard University Press.

Barros Neto, J. P. (2002). Teorias da Administração. Rio de Janeiro: Qualitymark.

Bradley, J. H.; Hebert, F. J. (1997). The effect of personality type on team performance. Journal of Management Development, 16(5), 337-353.

Cheney, P. H.; Hale, D. P.; Kasper, G. M. (1989). information systems professionals: skills for the 1990s. Em Proceedings Of The $22^{\text {nd }}$ Annual Hawaii International Conference On Systems Sciences. Washington, D. C., 331-6.

Couger, J., O'callaghan, R. (1993). comparing the motivation of spanish computer personnel with that of computer personnel in finland and the united states. University Of Navarra. Barcelona. Research Paper, 257, 1-16.

Drucker, P. F. (1967). O gerente eficaz. Rio de Janeiro: Editora Guanabara.

Faraj, S., Sproull, L. (2000). Coordinating expertise in software development teams. Management Science, 46(12), 1554-1568.

Faria, J. C. (1994). Administração: introdução ao estudo. São Paulo: Livraria Pioneira Editora.

Fayol, H. (1994, 10 ed.). Administração Industrial e Geral: previsão, organização, comando, coordenação, controle. São Paulo: Atlas. (Originalmente publicado em 1916) 
Gorla, N.; Lam, Y. W. (2004). Who should work with whom? Building effective software project teams. Communication of the ACM. 47(6), 79-82.

Hampton, D. R. (1990). Administração: processos administrativos. São Paulo: McGraw-Hill.

Holland, J. L. (1997, 30 a ed.). Making vocational choices: a theory of vocational personalities and work environments. Odessa: Psychological Assesment Resources.

Kanitz, S. (2005). A era do administrador. Revista Veja, 1886 (1), 21.

Klopfer, B. (1952). Técnica del psicodiagnostico de Rorschach. Buenos Aires: Ed. Paidos.

Kraut, R. E.; Streeter, L. A. (1995). Coordination in Software Development. Communication of the ACM, 38(3), 69-81.

McConnell, S. (1996). Rapid development. Washington: Microsoft Press.

McGregor, D. (1992, $2^{\text {a }}$ ed.). O lado humano da empresa. São Paulo: Martins Fontes. (Originalmente publicado em 1960)

Megginson, L. C.; Mosley, D. C.; Pietri, P. H. Jr. (1986). Administração - conceitos e aplicações. São Paulo: Harbra.

Mintzberg, H. (1975). The manager's Job: Folklore and Fact. Harvard Business Review, 49-61, july-august.

Mintzberg, H.; Gosling, J. (2003). Educando administradores além das fronteiras. RAE, 43(2), 29-43.

Moore, J. E. (1991). Personality characteristics of information systems professionals. Special intrest group on computer personnel research annual conference. Proceedings of The 1991. Athens, Georgia, 140-155.

Moscovici, F. (2003, $13^{\mathrm{a}}$ ed.). Desenvolvimento Interpessoal. Rio de Janeiro: José Olympio.

Motta, P. R. (2002, $8^{\mathrm{a}}$ ed.). A Ciência e a arte de ser dirigente. Rio de Janeiro: Record.
Oliveira, M. I. G. (1999) Trabalho, sofrimento e prazer a partir da revolução da informática. Trabalho de Conclusão de Curso Não-Publicada, Curso de Graduação em Psicologia, Pontifícia Universidade Católica de São Paulo.

Project Mangement Institute (2005). Disponível em <http://www.pmi.org>. (acessado em 10/01/05)

Rorschach, H. (1921). Psychodiagnostics. Berna: Bircher (Hans Huber Verlag's English Version, 1942)

Santos, S. C. G.; Vaz, C. E. (2004). O Rorschach, a capacidade de relacionamento e integração humana em homens e mulheres informatas. Em C. E. Vaz; R. L. Graeff (Orgs.), Técnicas Projetivas - Produtividade em Pesquisa (pp. 343-350). Porto Alegre: Casa do Psicólogo.

Stábile, S. (2001). Um estudo sobre a desconexão entre usuários e desenvolvedores de sistemas de informação e sua influência na obtenção de informação pelo decisor. Dissertação de Mestrado Não-Publicada, Escola de Engenharia de São Carlos, Universidade de São Paulo.

Taylor, F. W. (1995, $8^{\text {a }}$ ed.). Princípios de administração científica. São Paulo: Atlas. (Originalmente publicado em 1911)

Vaz, C. E. (1997, $3^{\text {a }}$ ed.). O Rorschach-Teoria e Desempenho. São Paulo: Editora Manole Ltda.

Vaz, C. E. (2002, 2 ${ }^{\mathrm{a}}$.ed.). Z-Teste Técnica de Zulliger - Forma Coletiva. São Paulo: Casa do Psicólogo.

Wynekoop, J. L.; Walz, D. B. (1998). Revisiting The perennial question: are is people diferent? The data base for advances in information systems, 29(2), 62-72.

Recebido em 21/03/2005 Aceito em 30/08/2005

Endereço para correspondência: Seille C. Garcia Santos, Rua Licínio Cardoso, 350, Chácara das Pedras, CEP 91330-470, Porto Alegre-RS. E-mail: seille@brturbo.com.br 